\title{
The rapid hydrolysis of chlordiazepoxide to demoxepam may affect the outcome of chronic osmotic minipump studies
}

\author{
Christiaan H. Vinkers • Gerdien A. H. Korte-Bouws • Javier Sastre Toraño • \\ Naheed R. Mirza • Elsebet Ø. Nielsen • Philip K. Ahring • Gerhardus J. de Jong • \\ Berend Olivier
}

Received: 5 September 2009 / Accepted: 2 December 2009/Published online: 13 January 2010

(C) The Author(s) 2010. This article is published with open access at Springerlink.com

\begin{abstract}
Background In chronic studies, the classical benzodiazepine chlordiazepoxide (CDP) is often the preferred drug because, unlike other benzodiazepines, it is soluble in water. However, rapid CDP hydrolysis in solution has been described. This would diminish plasma levels in chronic minipump studies and introduce the corelease of active compounds.

Methods Therefore, the present study aimed to explore the putative hydrolysis of CDP in aqueous solution over time and to identify the hydrolysis products. Moreover, we aimed to characterize the hydrolysis products for their in vitro $\left({ }^{3} \mathrm{H}\right.$-flunitrazepam binding and oocyte electrophysiology) and in vivo (stress-induced hyperthermia paradigm) $\mathrm{GABA}_{\mathrm{A}}$ receptor potency.
\end{abstract}

C. H. Vinkers $(\bowtie) \cdot$ G. A. H. Korte-Bouws $\cdot$ B. Olivier

Department of Psychopharmacology,

Utrecht Institute for Pharmaceutical Sciences (UIPS),

Faculty of Science, Utrecht University,

Sorbonnelaan 16 ,

3584 CA Utrecht, The Netherlands

e-mail: c.h.vinkers@uu.nl

C. H. Vinkers $\cdot$ G. A. H. Korte-Bouws $\cdot$ B. Olivier

Rudolf Magnus Institute of Neuroscience, Utrecht University,

Utrecht, The Netherlands

J. Sastre Toraño $\cdot$ G. J. de Jong

Department of Biomedical Analysis, Utrecht Institute

for Pharmaceutical Sciences (UIPS),

Utrecht University,

Utrecht, The Netherlands

N. R. Mirza $\cdot$ E. Ø. Nielsen • P. K. Ahring

Department of Pharmacology, NeuroSearch A/S,

Ballerup, Denmark

B. Olivier

Department of Psychiatry, School of Medicine, Yale University,

New Haven, CT, USA
Results CDP in solution hydrolyzed to the ketone structure demoxepam which was confirmed using mass spectrometry. The hydrolysis was concentration dependent (first-order kinetics) and temperature dependent. CDP exerted greater potency compared to demoxepam in vitro (increased activity at $\mathrm{GABA}_{\mathrm{A}}$ receptors containing $\alpha_{1}$ subunits) and in vivo (stress-induced hyperthermia), although ${ }^{3} \mathrm{H}$-flunitrazepam binding was comparable.

Conclusions The classical benzodiazepine CDP is rapidly hydrolyzed in solution to the active compound demoxepam which possesses a reduced activity at the $\mathrm{GABA}_{\mathrm{A}}$ receptor. Chronic studies that use CDP in aqueous solution should thus be interpreted with caution. It is therefore important to consider drug stability in chronic minipump applications.

Keywords Benzodiazepine - Chronic · Degradation ·

$\mathrm{GABA}_{\mathrm{A}}$ receptor

$\begin{array}{ll}\text { Abbreviations } \\ \text { CDP } & \text { Chlordiazepoxide } \\ \text { CID } & \text { Collision-induced dissociation } \\ \text { MS } & \text { Mass spectrometry } \\ \text { SIH } & \text { Stress-induced hyperthermia } \\ \text { SEM } & \text { Standard error of the mean }\end{array}$

Introduction

The $\mathrm{GABA}_{\mathrm{A}}$ receptor is the main inhibitory receptor in the central nervous system known to be closely involved in stress and anxiety processes. Classical (nonselective) benzodiazepines are clinically relevant anxiolytic drugs that act on $\mathrm{GABA}_{\mathrm{A}}$ receptors, allosterically enhancing the inhibitory GABA actions by binding to $\alpha_{1}, \alpha_{2}, \alpha_{3}$, or $\alpha_{5}$ 
subunits (Rudolph and Mohler 2006). Besides the preferred anxiolytic action, benzodiazepines possess a wide variety of adverse effects, including dependence, tolerance, withdrawal, sedation, and cognitive impairing effects. Recently, the concept that distinct $\mathrm{GABA}_{\mathrm{A}}$ receptor $\alpha$ subtypes generate specific (side) effects has led to an increasing body of research studying the acute and chronic effects of classical benzodiazepines (Crestani et al. 2001; Rudolph et al. 1999).

In clinical practice, benzodiazepines are usually prescribed for a longer period (ranging from weeks, months to even years). Animal studies that aim to elucidate the largely unknown mechanisms underlying the chronic benzodiazepine (side) effects either administer drugs manually or use osmotic minipumps (hereafter referred to as "minipumps"). The main advantage of osmotic minipumps is a continuous drug release for a longer period whereas no animal handling is needed during the entire delivery period. However, when loaded into a minipump, a drug needs to be dissolved in order to reach the desired controlled delivery. If a compound cannot be dissolved or is unstable in solution, this may have enormous consequences for the interpretation of minipump studies (van der Zwaal et al. 2008).

When designing chronic minipump studies using classical benzodiazepines, chlordiazepoxide (CDP) is often the preferred drug of choice (e.g., Kas et al. 2008; West and Weiss 2005) because it - in contrast to most other classical benzodiazepines - is soluble in water (1:10; Moffat et al. 2004). However, the rapid hydrolysis of CDP in aqueous solution to the active ketone product demoxepam has been described (Han et al. 1976). This would diminish CDP plasma levels in minipump studies over time and introduce an active second compound that would be coreleased from the minipump. Therefore, the present study aimed to explore the putative hydrolysis of the classical benzodiazepine CDP in aqueous solution and in minipumps over time and to identify the hydrolysis products using mass spectrometry. Moreover, we characterized the hydrolysis products for their in vitro $\left({ }^{3} \mathrm{H}\right.$-flunitrazepam binding and oocyte electrophysiology) and in vivo (stress-induced hyperthermia $(\mathrm{SIH})$ paradigm) $\mathrm{GABA}_{\mathrm{A}}$ receptor potency. The present study indicates that, although the use of minipumps present in chronic studies presents a valid alternative, drug stability and release should always be considered and, when needed, carefully be investigated.

\section{Materials and methods}

\section{Drugs}

Chlordiazepoxide $\mathrm{HCl}$ (Pharbita, Zaandam, The Netherlands) was freshly dissolved at each testing day. Demoxepam was obtained by keeping CDP at a concentration of
$2 \mathrm{mg} / \mathrm{ml}$ at a temperature of $37^{\circ} \mathrm{C}$ for 40 days. Subsequently, it was filtered through a $0.2-\mu \mathrm{m}$ filter and stored at $-80^{\circ} \mathrm{C}$. Frozen demoxepam aliquots were defrosted shortly before experiments.

Identification of the chlordiazepoxide hydrolysis products using LC-MS/MS

To confirm the identity of the CDP hydrolysis products, a liquid chromatography-mass spectrometry (LC-MS)/MS setup was used. Chlordiazepoxide $\mathrm{HCl}$ (throughout the present study, CDP in the salt form was used) at a concentration of $2 \mathrm{mg} / \mathrm{ml}$ was kept for 40 days at a temperature of $37^{\circ} \mathrm{C}$ and subsequently stored at $-80^{\circ} \mathrm{C}$. The solution was then analyzed using a liquid chromatography system and an Agilent 1100 Series LC/MSD SL ion-trap mass spectrometer equipped with an electrospray ionization source (MS, Agilent Technologies). The mobile phase consisted of $100 \mathrm{mM}$ ammonium formate $(\mathrm{pH} 4.5)$ methanol $(1: 1, v / v)$, and the flow rate was $0.5 \mathrm{ml} / \mathrm{min}$. The MS was operated in positive ion mode, the electrospray voltage was optimized and set to $+3.5 \mathrm{kV}$, and lens voltages were optimized for maximal signal intensity. The nebulizing gas pressure was adjusted to $50 \mathrm{psi}(345 \mathrm{kPa})$, and the flow of the drying gas to $10 \mathrm{l} / \mathrm{min}$ with a drying temperature of $350^{\circ} \mathrm{C}$. The scan range was $140-310 \mathrm{~m} / \mathrm{z}$, and five scans were averaged for one spectrum. Collisioninduced dissociation (CID) with helium as collision gas was performed on the protonated molecular ion $\left([\mathrm{M}+\mathrm{H}]^{+}\right)$of the degradation product. The $\mathrm{m} / \mathrm{z}$ values of the precursor ion was manually selected, and the collision energy was set to the instrument default value of $100 \%(1.00 \mathrm{~V})$, resulting in significant presence of fragmentation ions.

\section{Stability of chlordiazepoxide in solution}

To investigate the hydrolysis kinetics under various concentrations and environmental temperature conditions, the stability of a standard CDP solution was studied using a $10 \mu \mathrm{g} / \mathrm{ml} \mathrm{CDP}$ solution that was stored in a thermostated autosampler at a temperature of $37^{\circ} \mathrm{C}$. These samples were analyzed over time in the next 45 days. Furthermore, the influence of environmental temperature on CDP hydrolysis was studied by storing a $2-\mathrm{mg} / \mathrm{ml}$ CDP solution at various temperatures with subsequent analysis over time. Concentration-dependent hydrolysis was studied by storing CDP solutions at three different concentrations $(0.02,0.2$, and $2 \mathrm{mg} / \mathrm{ml})$ at $37^{\circ} \mathrm{C}$ during 35 days which were subsequently analyzed. For all samples, CDP and putative hydrolysis products were detected simultaneously by HPLC with UV detection at a wavelength of $254 \mathrm{~nm}$ (Spectroflow 757 Kratos Analytical). The system consisted of a pump 
(SpectraSeries P100 Thermo Separation products), a vacuum degasser (ERC-3113 Erma CR Inc., Tokyo, Japan), an autosampler (SpectraSeries AS300 Thermo Separation products), a column (Hypersil BDS $150 \mathrm{~mm} \times 4.6 \mathrm{~mm} \times 5 \mu \mathrm{m})$, and a detector. The mobile phase consisted of $50 \mathrm{mM}$ phosphoric acid $(\mathrm{pH}$ 6.5) in $50 \%$ methanol and was pumped at $0.5 \mathrm{ml} / \mathrm{min}$. From each sample, $100 \mu \mathrm{l}$ was injected onto the column. The chromatograms were recorded and analyzed using the Atlast 2003 chromatography data handling system (Thermo Election Corporation, Altrincham, UK). For degradation plots, the peak area of demoxepam after 35 days was set at $100-(\% \mathrm{CDP})$.

Chlordiazepoxide delivery rates from osmotic minipumps

To confirm that chlordiazepoxide delivery would indeed decline over time, three osmotic minipumps (Alzet, 2004 model, pumping rate $0.25 \mu \mathrm{g} / \mathrm{h}$ during 28 days) were filled with a CDP solution $(2 \mathrm{mg} / \mathrm{ml})$. Osmotic minipumps were put into separate tubes containing $7.0 \mathrm{ml}$ of saline and were kept at $37^{\circ} \mathrm{C}$. Minipumps were transferred regularly to novel saline tubes for 5 weeks. The concentrations CDP and demoxepam were determined using an identical HPLC with UV setup as above.

In vitro ${ }^{3} \mathrm{H}$-flunitrazepam binding and oocyte electrophysiology

To assess the in vitro affinity and efficacy of CDP and demoxepam for the $\mathrm{GABA}_{\mathrm{A}}$ receptor, in vitro ${ }^{3} \mathrm{H}$-flunitrazepam and oocyte electrophysiology experiments were carried out. In vitro ${ }^{3} \mathrm{H}$-flunitrazepam binding was done as described previously (Mirza et al. 2008). Shortly, aliquots of $500 \mu \mathrm{l}$ of rat cortical membranes were added to $25 \mu \mathrm{l}$ of test compound, and $25 \mu \mathrm{l}(1 \mathrm{nM}$, final concentration) of ${ }^{3} \mathrm{H}$-flunitrazepam ( $88 \mathrm{Ci} / \mathrm{mmol}$; GE Healthcare) was mixed and incubated for $40 \mathrm{~min}$ at $2{ }^{\circ} \mathrm{C}$. Binding was terminated by rapid filtration, and the amount of radioactivity on the filters was determined by conventional liquid scintillation counting. Electrophysiological responses from $\mathrm{GABA}_{\mathrm{A}}$ receptors expressed in Xenopus laevis oocytes were measured using the two-electrode voltage-clamp technique as described previously (Mirza et al. 2008). Briefly, GABA was freshly dissolved in OR2 in a concentration known to elicit $\mathrm{EC}_{5}$ $\mathrm{EC}_{25}$ currents for a given $\mathrm{GABA}_{\mathrm{A}}$ receptor subtype combination $(0.5-5 \mu \mathrm{M})$, and this solution was used for controls as well as a stock solution for dissolving demoxepam. Modulatory effects of demoxepam were calculated by comparing demoxepam traces to a prior GABA control trace. To enable comparison of effects between individual oocytes, demoxepam potentiations were normalized to a control $0.5-\mu \mathrm{M}$ diazepam potentiation on the same oocyte.
In vivo comparison of chlordiazepoxide and demoxepam

\section{The SIH procedure}

To screen for the anxiolytic and hypothermic potency of a CDP and demoxepam, the SIH paradigm was applied. The $\mathrm{SIH}$ paradigm uses the stress-induced increase in body temperature which is considered to be a functional body response in anticipation to physiological demands (preparation for fight or flight; Vinkers et al. 2008). In the SIH paradigm, classical as well as subunit-selective benzodiazepines consistently reduce the $\mathrm{SIH}$ response as well as basal body temperature levels at higher doses. In the present study, the SIH tests were carried out according to the standard procedures (Vinkers et al. 2009). Briefly, the rectal basal body temperature $\left(T_{1}\right)$ is measured and functions as a stressor as well and is followed $10 \mathrm{~min}$ later by a second rectal temperature measurement $T_{2}$ that reflects the stress-induced body temperature. The difference $(\Delta T=$ $T_{2}-T_{1}$ ) is the $\mathrm{SIH}$ response. A between-subject design was used. Cages were randomly and evenly allocated over daytimes (morning-afternoon). The temperature of mice was measured by rectally inserting a thermistor probe by a length of $2 \mathrm{~cm}$. Digital temperature recordings were obtained with an accuracy of $0.1^{\circ} \mathrm{C}$ using a Keithley 871A digital thermometer ( $\mathrm{NiCr}-\mathrm{NiAl}$ thermocouple). The probe, dipped into silicon oil before inserting, was held in the rectum until a stable rectal temperature had been obtained for 20 s. Animals were injected intraperitoneally with either CDP, demoxepam, or vehicle (intraperitoneally, $10 \mathrm{ml} / \mathrm{kg}$ ) $60 \mathrm{~min}$ before the first temperature measurement $\left(T_{1}\right)$. The temperature was again measured $10 \mathrm{~min}$ later $\left(T_{2}\right)$.

\section{Animals}

For in vivo experiments, male mice (129Sv/EvTac) were obtained from Taconic M\&B, Ry, Denmark. Animals were housed in Macrolon type 3 cages enriched with bedding and nesting material under a 12:12 light/dark cycle (lights on from 0600 to 1800 hours) at controlled temperature $\left(20 \pm 2^{\circ} \mathrm{C}\right)$ and relative humidity (40-60\%) with free access to standard food pellets and tap water. Experiments were carried out with approval of the ethical committee on animal experiments of the Faculties of Sciences, Utrecht University, The Netherlands, and in accordance with the Declaration of Helsinki.

\section{Statistics}

For each individual mouse, a basal temperature $\left(T_{1}\right)$, an end temperature $\left(T_{2}\right)$, and the difference $\left(\mathrm{SIH}\right.$ response $\left.=T_{2}-T_{1}\right)$ was determined. Treatment effects were evaluated using a one-way analysis of variance with explanatory factor treatment. If the overall analysis of variance appeared 
significant, post hoc tests (Dunnet's post hoc test) were used to identify significant differences.

\section{Results}

Identification of the chlordiazepoxide hydrolysis products using LC-MS/MS

The extracted ion chromatogram at $\mathrm{m} / \mathrm{z} 300.1$ showed the presence of CDP (Fig. 1b). The first and only eluting degradation product with $\mathrm{m} / \mathrm{z} 287.1$ was demoxepam, the CDP hydrolysis product after oxidative deamination (Fig. 1a). The typical mass spectra of $\mathrm{CDP}\left([\mathrm{M}+\mathrm{H}]^{+}=300.1\right)$ and the hydrolyzed product demoxepam $\left([\mathrm{M}+\mathrm{H}]^{+}=287.1\right)$, both with a typical chloride isotopic distribution pattern, are presented in Fig. 2. The identification of demoxepam (with a calculated monoisotopic mass of 286.1) was performed by MS/MS of $\mathrm{m} / \mathrm{z}$ 287.1. The resulting fragments (Fig. 2c) showed the loss of a hydroxyl (corresponding to a N-oxide benzodiazepine), a - $\mathrm{COH}$ (corresponding to a benzodiazepine with carbonyl group) and a phenyl group. The interpretation of the various fragments of demoxepam is in line with literature (Nedved et al. 1996; Risoli et al. 2007; Smyth et al. 2000).

Stability of chlordiazepoxide in solution

At $37^{\circ} \mathrm{C}$, CDP was rapidly degraded into demoxepam with a half-time of around 8.8 days (Fig. 3a). CDP hydrolysis strictly followed first-order kinetics $\left([\mathrm{CDP}]_{t}=[\mathrm{CDP}]_{0} \times e^{-k t}\right.$ with $t$ being time and $k$ being the first-order rate constant) and was temperature dependent. At storage conditions below $0^{\circ} \mathrm{C}$, no apparent hydrolysis occurred (Fig. 3b). Identical to the results at $-25^{\circ} \mathrm{C}$, storage conditions at $-80^{\circ} \mathrm{C}$ did not result in any hydrolysis (data not shown). In line with first-order kinetics, CDP hydrolysis was concentration dependent (Fig. 3c).

Chlordiazepoxide delivery rates from osmotic minipumps

CDP release from the minipump $(n=3)$ declined over time (Fig. 4a, black symbols). After 28 days, only $25 \%$ of all CDP was released from the minipumps. When the cumulative CDP concentration over time was corrected for its hydrolysis, drug release from the minipumps followed the theoretical release profile over time (white symbols), suggesting that CDP hydrolysis completely accounted for the declined CDP release over time.

In vitro ${ }^{3} \mathrm{H}$-flunitrazepam binding and oocyte electrophysiology

Chlordiazepoxide and demoxepam both displayed comparable affinity for rat $\mathrm{GABA}_{\mathrm{A}}$ benzodiazepine binding sites labeled by ${ }^{3} \mathrm{H}$-flunitrazepam (Table 1). However, demoxepam showed less efficacy for $\alpha_{1} \beta_{2} \gamma_{2} G_{A B A}$ receptors compared to CDP, whereas efficacy at $\alpha_{3} \beta_{2} \gamma_{2} \mathrm{GABA}_{\mathrm{A}}$ receptors was comparable (Fig. 5)
Fig. 1 Extracted ion traces of demoxepam (a) and chlordiazepoxide (b) obtained by LC-MS of a $2-\mathrm{mg} / \mathrm{ml}$ chlordiazepoxide solution kept for 35 days at $37^{\circ} \mathrm{C}$

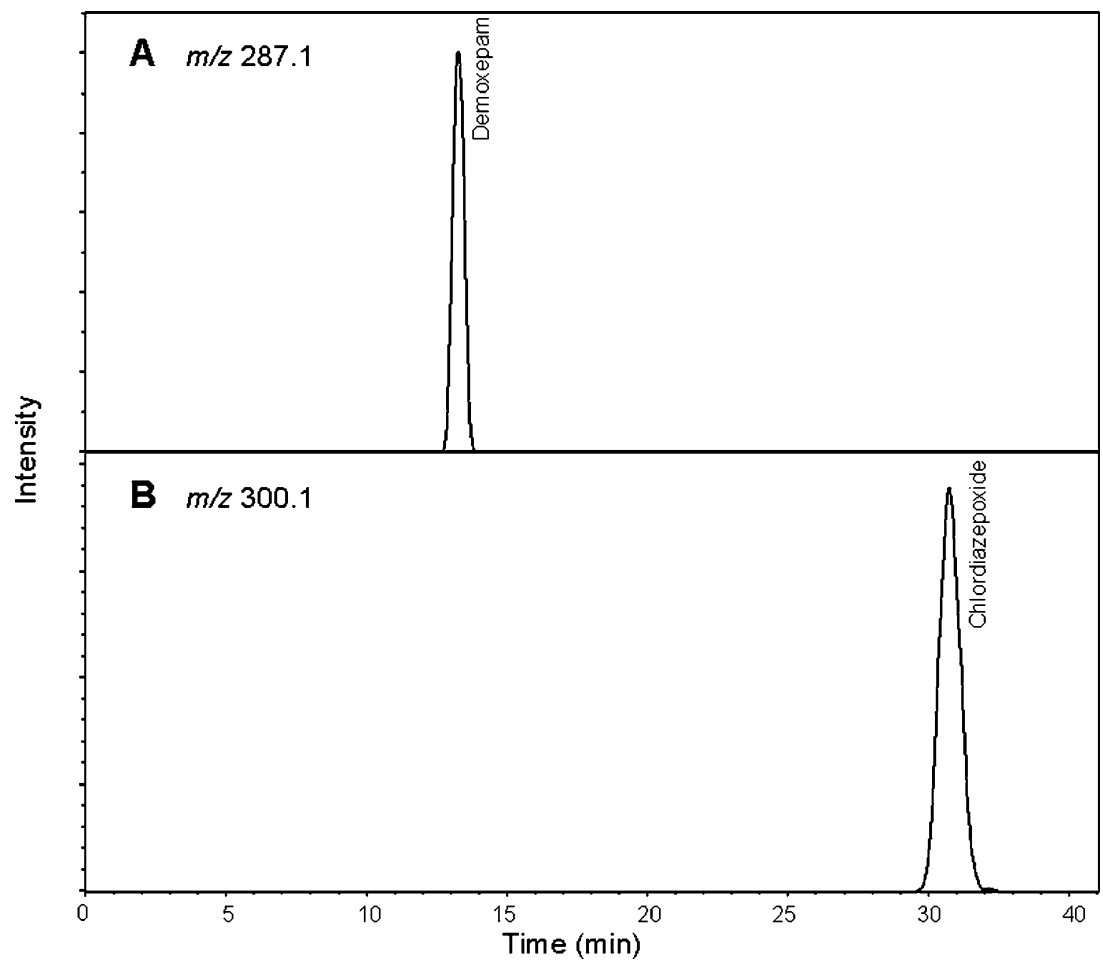


Fig. 2 Mass spectra and molecular structures of demoxepam with $[\mathrm{M}+\mathrm{H}]^{+} 287.1$ (a) and chlordiazepoxide with $[\mathrm{M}+\mathrm{H}]^{+}$ 300.1 (b) obtained by LC-MS analysis of the mixture of chlordiazepoxide and demoxepam in the $2-\mathrm{mg} / \mathrm{ml}$ chlordiazepoxide solution kept for 35 days at $37^{\circ} \mathrm{C}$. The CID mass spectrum of $\mathrm{m} / \mathrm{z} 287.1$ confirmed the presence of demoxepam (c)

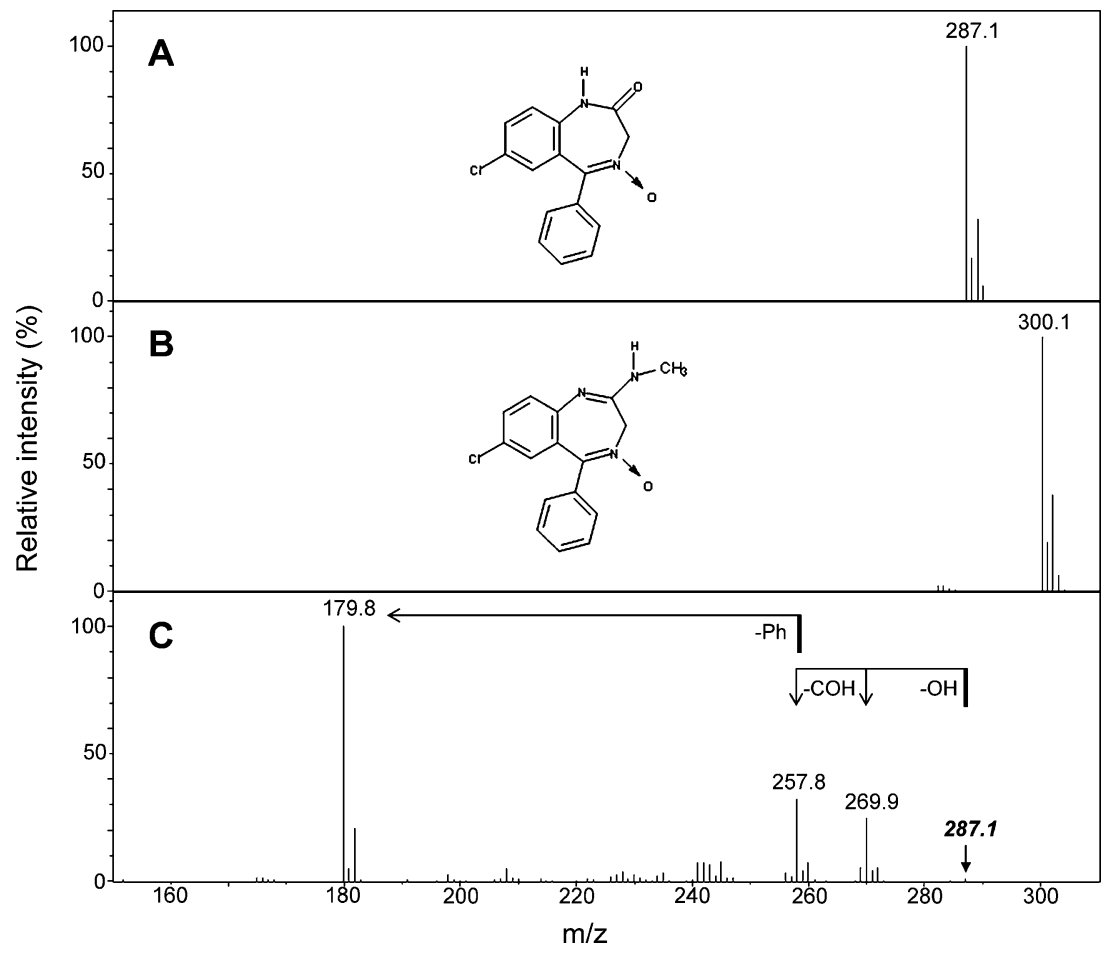

In vivo comparison of chlordiazepoxide and demoxepam

CDP and demoxepam overall reduced SIH (drug effect $\left.F_{5,69}=11.91, p<0.001\right)$ as well as basal body temperature (drug effect $F_{5},{ }_{69}=9.46, p<0.001$; Fig. 6). Post hoc testing revealed that CDP lowered basal body temperature at $10 \mathrm{mg} / \mathrm{kg}(p<0.05)$ as well as $20 \mathrm{mg} / \mathrm{kg}(p<0.001)$, whereas demoxepam lowered basal body temperature only at its highest dose of $40 \mathrm{mg} / \mathrm{kg} \quad(p<0.05)$. Planned comparisons showed that CDP at a dose of $20 \mathrm{mg} / \mathrm{kg}$ had a stronger effect on basal body temperature $\left(F_{1,23}=\right.$ $9.49, p<0.01)$ as well as $\mathrm{SIH}$ attenuation $\left(F_{1,23}=6.35\right.$, $p<0.05)$ compared to demoxepam $20 \mathrm{mg} / \mathrm{kg}$. When we compared CDP $20 \mathrm{mg} / \mathrm{kg}$ to demoxepam $40 \mathrm{mg} / \mathrm{kg}$, there were no differences in basal body temperature $\left(F_{1,21}=\right.$ $0.001, p=0.97, \mathrm{NS})$ nor $\mathrm{SIH}$ reduction $\left(F_{1,21}=0.01\right.$, $p=0.98$, NS). CDP thus more potently reduced basal body temperature as well as the $\mathrm{SIH}$ response compared to demoxepam. Demoxepam reached the anxiolytic and hypothermic effects of CDP at higher doses.

\section{Discussion}

The present study shows that CDP in solution rapidly hydrolyzes to the ketone structure demoxepam with a halftime of around 9 days at $37^{\circ} \mathrm{C}$, thus confirming earlier reports on CDP hydrolysis (Han et al. 1976). Using mass spectrometry, we confirmed that the single hydrolysis product is indeed demoxepam, arising from oxidative deamination of CDP (Figs. 1 and 2). The CDP hydrolysis was concentration dependent (following first-order kinetics) as well as temperature dependent (Fig. 3b, c). In osmotic minipumps, hydrolysis to demoxepam was again apparent
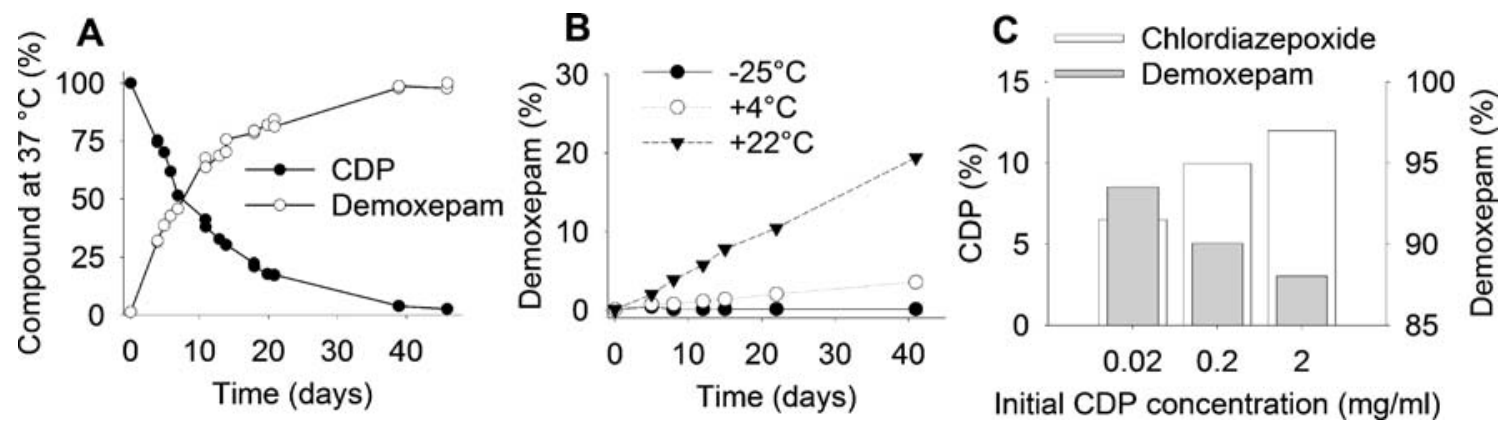

Fig. 3 Chlordiazepoxide $(2 \mathrm{mg} / \mathrm{ml})$ rapidly hydrolyzes into demoxepam at $37^{\circ} \mathrm{C}(\mathbf{a})$. This hydrolysis rate is absent at lower temperatures $(\mathbf{b})$ and concentration dependent (c; compound after 35 days at $37^{\circ} \mathrm{C}$ ) 


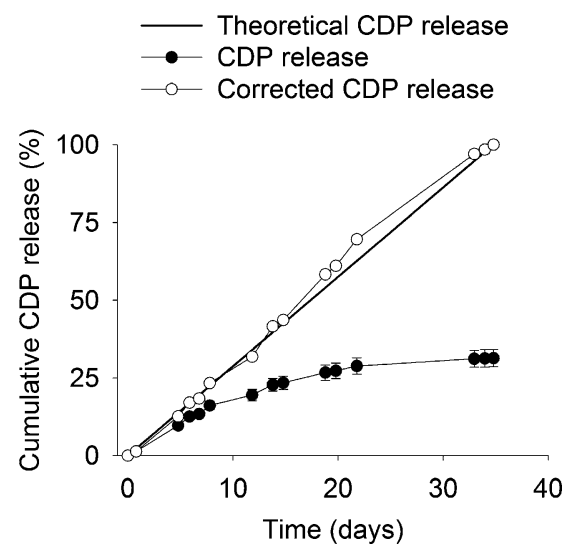

Fig. 4 Release of chlordiazepoxide $(2 \mathrm{mg} / \mathrm{ml})$ from osmotic minipumps $(n=3)$ over time. CDP release declines over time (black symbols). When CDP hydrolysis is taken into account, CDP release follows the theoretical curve (white symbols), indicating that it is CDP hydrolysis that leads to declined CDP release

(Fig. 4). Demoxepam is already known as an active metabolite of CDP with a half-life markedly longer than that of CDP (Schwartz et al. 1971) and with steady-state concentrations exceeding those of CDP (Roy-Byrne et al. 1996). In contrast to another study, we did not find a parallel degradation of demoxepam to a 2-amino-5-chlorobenzophenone and a glycine derivative (Han et al. 1976), although we cannot exclude the possibility that hydrolysis products were present which were not eluted in time to be detected.

Using the stress-induced hyperthermia paradigm (Vinkers et al. 2008), our data in mice suggest that CDP may exert greater acute potency compared to demoxepam (Fig. 5). Interestingly, a study that found significant dependence after chronic CDP administration showed low CDP blood levels and high metabolite levels, indicating that demoxepam is indeed active (Chan et al. 1989). Another study in subjects suffering from anxiety disorder found a significant correlation between anxiety reduction and demoxepam plasma levels but not CDP plasma levels, suggesting that after chronic exposure, demoxepam may possess anxiolytic effects that surpass those of CDP itself (Lin and Friedel 1979). Demoxepam binding data to oocyte $\mathrm{GABA}_{\mathrm{A}}$ receptors containing $\alpha_{1}$ and $\alpha_{3}$ receptors showed that demoxepam displayed lower efficacy at $\alpha_{1}$ containing $\mathrm{GABA}_{\mathrm{A}}$ receptors, even though in vitro ${ }^{3} \mathrm{H}$-flunitrazepam binding was not different. Thus, the active metabolites

Table 1 Inhibition of ${ }^{3} \mathrm{H}$-flunitrazepam binding to rat cortical membranes by chlordiazepoxide and demoxepam. Data are mean \pm SEM, $n=3-4$ experiments

Compound

${ }^{3} \mathrm{H}$-flunitrazepam binding $(\mathrm{Ki}, \mu \mathrm{M})$

Chlordiazepoxide

$0.67 \pm 0.10$

Demoxepam

$0.44 \pm 0.02$
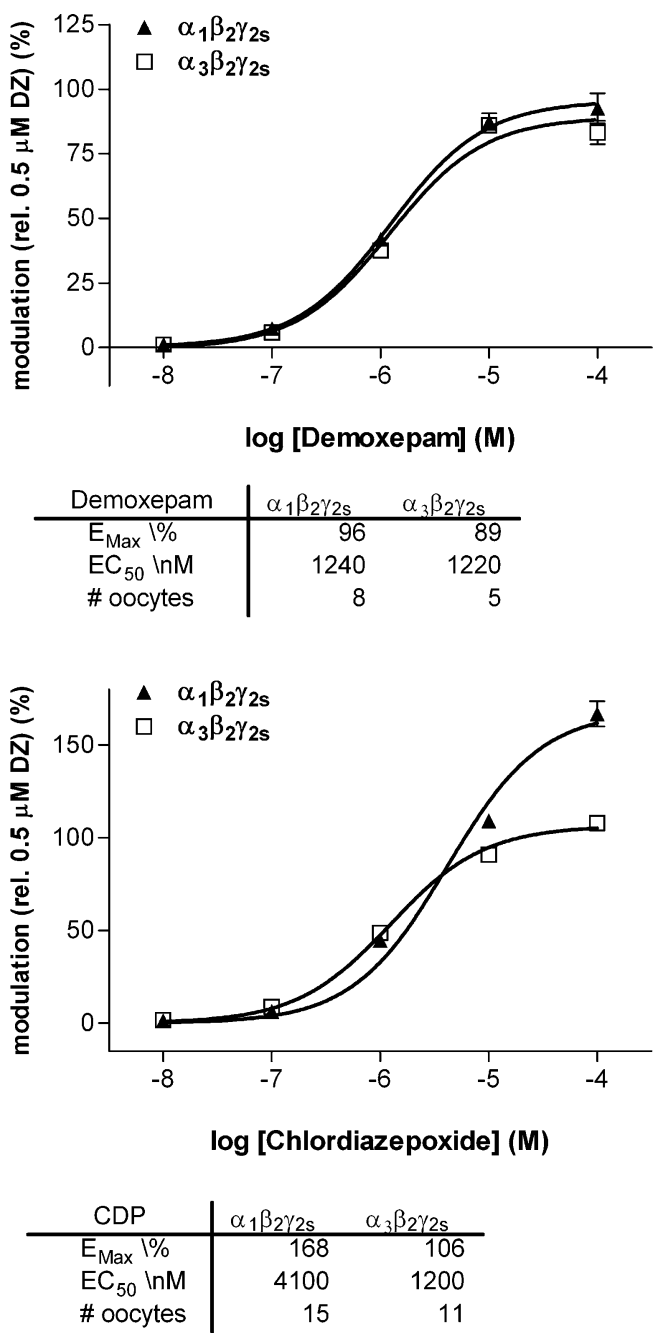

Fig. 5 Efficacy (compared to diazepam) of demoxepam (upper figure) and chlordiazepoxide (lower figure) in oocytes expressing $\mathrm{GABA}_{\mathrm{A}}$ receptors containing $\alpha_{1}$ and $\alpha_{3}$ subunits

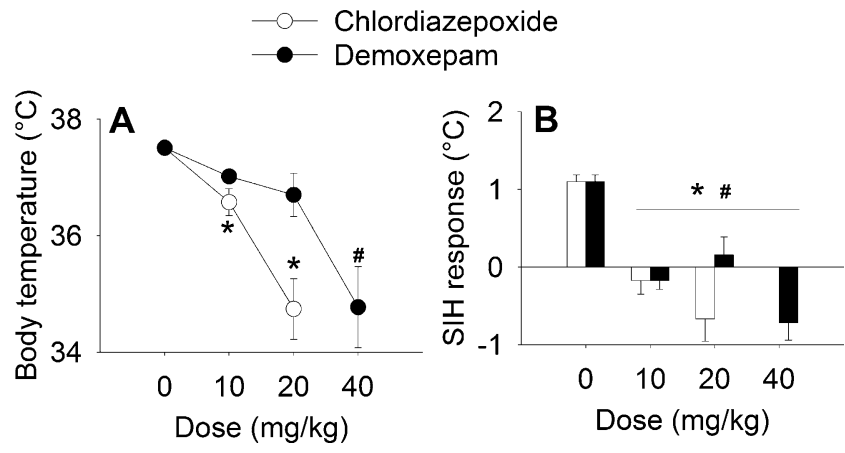

Fig. 6 In vivo efficacy of chlordiazepoxide $(0-20 \mathrm{mg} / \mathrm{kg}$, IP) and demoxepam $(0-40 \mathrm{mg} / \mathrm{kg}$, IP) on the basal body temperature (a) and the stress-induced hyperthermia response (b) in 129Sv mice $(n=10$ 12). $* p<0.05$ CDP compared to vehicle; $\# p<0.05$ demoxepam compared to vehicle 
(including demoxepam) may significantly contribute to the various effects of CDP.

The apparent hydrolysis of CDP in solution was previously not taken into consideration in chronic experiments that used osmotic minipumps. Results obtained from chronic CDP administration using osmotic minipumps may be (partially) ascribed to demoxepam or the combination of both rather than to only CDP itself. Studies that have tested dissolved CDP in osmotic minipumps have yielded variable results. In one study, chronic minipump treatment with CDP $(10 \mathrm{mg} / \mathrm{kg} /$ day $)$ prevented hyperalgesia in rats subjected to a social-defeat procedure (Alexandre et al. 2006), and in another study, 7-14-day minipump treatment with CDP $(10 \mathrm{mg} / \mathrm{kg} /$ day $)$ increased $\mathrm{GABA}_{\mathrm{A}}$ receptor desensitization in rats, as well as tolerance in an elevatedplus-maze test (Cash et al. 1997). One-week CDP minipump treatment $(5-10 \mathrm{mg} / \mathrm{kg} /$ day) in $\mathrm{C} 57 \mathrm{BL} / 6 \mathrm{~J}$ mice reduced sheltered feeding preference without altering motor activity levels (Kas et al. 2008). In contrast, 14-day CDP minipump treatment $(2 \mathrm{mg} / \mathrm{kg} /$ day $)$ did not prevent the stress-induced decrease in swim-test struggling in rats unlike chronic treatment with different antidepressant drugs (West and Weiss 2005). Only in one study, plasma concentrations of CDP and its metabolites were determined after 14 days (Cash et al. 1997). The extent to which CDP hydrolysis may have altered the outcomes in these studies cannot be determined as the active product demoxepam was formed. However, because demoxepam is less potent compared to CDP, an underestimation of the CDP effects is possible.

An alternative to minipump administration is the chronic application of repeated daily injections. However, adequate plasma levels are not easily established, and repetitive injections may affect experimental outcomes, especially in stress-related research. In a study that compared daily injections with minipumps, chronic diazepam administration resulted in sedative tolerance under both conditions, although tolerance to the anxiolytic effects was only present after the daily injections (Fernandes et al. 1999). This suggests that both ways of establishing chronic benzodiazepine exposure may not yield identical results. To complicate things even further, withdrawal anxiety from chronic diazepam treatment by manual daily injections was found to depend on administration route as it was present after subcutaneous but not after intraperitoneal injections (Allison and Pratt 2006).

In conclusion, the present study indicates that the classical benzodiazepine CDP is rapidly hydrolyzed in solution to the active compound demoxepam. The fact that CDP is readily soluble in water makes it an attractive choice for minipump applications, but it immediately poses the researcher for some challenges. As the exact anxiolytic contributions of CDP and its active hydrolysis product demoxepam are hard to dissect and the ratio CDP/ demoxepam is not stable over time in solution, we advise that chronic CDP applications in which CDP is dissolved should be interpreted with caution. The possibility of using more lipophilic classical benzodiazepines (e.g., diazepam) in minipumps with solid PEG-400 dispersions may present a valid alternative (Verheyen et al. 2002). Although we only studied the degradation of CDP, it is conceivable that other drugs may also be subject to degradation in chronic minipump studies, including olanzapine (van der Zwaal et al. 2008), zopiclone (Fernandez et al. 2004), and sulpiride (Abdelal et al. 2009). In general, the use of osmotic minipumps presents a valid and attractive alternative to the labor-intensive daily injections. However, the issue of drug stability and release should always be carefully investigated before initiating chronic minipump experiments.

Acknowledgments The authors would like to thank Dr. J.H. van den Berg for carefully reading the manuscript.

Conflicts of interest The authors declare no financial disclosures or conflicts of interest.

Open Access This article is distributed under the terms of the Creative Commons Attribution Noncommercial License which permits any noncommercial use, distribution, and reproduction in any medium, provided the original author(s) and source are credited.

\section{References}

Abdelal, A, El-Enany N et al (2009) Simultaneous determination of sulpiride and its alkaline degradation product by second derivative synchronous fluorescence spectroscopy. Talanta 80 (2):880-888

Alexandre C, Popa D, Fabre V, Bouali S, Venault P, Lesch KP, Hamon M, Adrien J (2006) Early life blockade of 5-hydroxytryptamine $1 \mathrm{~A}$ receptors normalizes sleep and depression-like behavior in adult knock-out mice lacking the serotonin transporter. J Neurosci $26: 5554-5564$

Allison C, Pratt JA (2006) Differential effects of two chronic diazepam treatment regimes on withdrawal anxiety and AMPA receptor characteristics. Neuropsychopharmacology 31:602-619

Cash DJ, Serfozo P, Allan AM (1997) Desensitization of a gammaaminobutyric acid type A receptor in rat is increased by chronic treatment with chlordiazepoxide: a molecular mechanism of dependence. J Pharmacol Exp Ther 283:704-711

Chan AW, Leong FW, Schanley DL, Langan MC, Penetrante ML (1989) A liquid diet model of chlordiazepoxide dependence in mice. Pharmacol Biochem Behav 34:839-845

Crestani F, Low K, Keist R, Mandelli M, Mohler H, Rudolph U (2001) Molecular targets for the myorelaxant action of diazepam. Mol Pharmacol 59:442-445

Fernandes C, Arnot MI, Irvine EE, Bateson AN, Martin IL, File SE (1999) The effect of treatment regimen on the development of tolerance to the sedative and anxiolytic effects of diazepam. Psychopharmacology (Berl) 145:251-259 
Fernandez C, Gimenez F et al (2004) Degradation and racemization of zopiclone enantiomers in plasma and partially aqueous solutions. Chirality 7(4):267-271

Han WW, Yakatan GJ, Maness DD (1976) Kinetics and mechanisms of hydrolysis of 1, 4-benzodiazepines I: chlordiazepoxide and demoxepam. J Pharm Sci 65:1198-1204

Kas MJ, de Mooij-van Malsen AJ, Olivier B, Spruijt BM, van Ree JM (2008) Differential genetic regulation of motor activity and anxiety-related behaviors in mice using an automated home cage task. Behav Neurosci 122:769-776

Lin KM, Friedel RO (1979) Relationship of plasma levels of chlordiazepoxide and metabolites to clinical response. Am J Psychiatry 136:18-23

Mirza NR, Larsen JS, Mathiasen C, Jacobsen TA, Munro G, Erichsen HK, Nielsen AN, Troelsen KB, Nielsen EO, Ahring PK (2008) NS11394 [3'-[5-(1-hydroxy-1-methyl-ethyl)-benzoimidazol-1yl]-biphenyl-2-carbonitr ile], a unique subtype-selective GABAA receptor positive allosteric modulator: in vitro actions, pharmacokinetic properties and in vivo anxiolytic efficacy. J Pharmacol Exp Ther 327:954-968

Moffat A, Osselton M, Widdop B (2004) Clarke's analysis of drugs and poisons. Pharmaceutical, London

Nedved ML, Habibi-Goudarzi S, Ganem B, Henion JD (1996) Characterization of benzodiazepine "combinatorial" chemical libraries by on-line immunoaffinity extraction, coupled column HPLC-ion spray mass spectrometry-tandem mass spectrometry. Anal Chem 68:4228-4236

Risoli A, Cheng JB, Verkerk UH, Zhao J, Ragno G, Hopkinson AC, Siu KW (2007) Gas-phase fragmentation of protonated benzodiazepines. Rapid Commun Mass Spectrom 21:2273-2281

Roy-Byrne P, Wingerson DK, Radant A, Greenblatt DJ, Cowley DS (1996) Reduced benzodiazepine sensitivity in patients with panic disorder: comparison with patients with obsessive-compulsive disorder and normal subjects. Am J Psychiatry 153:1444-1449
Rudolph U, Mohler H (2006) GABA-based therapeutic approaches: GABAA receptor subtype functions. Curr Opin Pharmacol 6:18-23

Rudolph U, Crestani F, Benke D, Brunig I, Benson JA, Fritschy JM, Martin JR, Bluethmann H, Mohler H (1999) Benzodiazepine actions mediated by specific gamma-aminobutyric acid(A) receptor subtypes. Nature 401:796-800

Schwartz MA, Postma E, Gaut Z (1971) Biological half-life of chlordiazepoxide and its metabolite, demoxepam, in man. J Pharm Sci 60:1500-1503

Smyth WF, McClean S, Ramachandran VN (2000) A study of the electrospray ionisation of pharmacologically significant 1, 4benzodiazepines and their subsequent fragmentation using an ion-trap mass spectrometer. Rapid Commun Mass Spectrom 14:2061-2069

van der Zwaal EM, Luijendijk MC, Adan RA, la Fleur SE (2008) Olanzapine-induced weight gain: chronic infusion using osmotic minipumps does not result in stable plasma levels due to degradation of olanzapine in solution. Eur J Pharmacol 585:130-136

Verheyen S, Blaton N, Kinget R, Van den Mooter G (2002) Mechanism of increased dissolution of diazepam and temazepam from polyethylene glycol 6000 solid dispersions. Int J Pharm 249:45-58

Vinkers $\mathrm{CH}$, van Bogaert MJ, Klanker M, Korte SM, Oosting R, Hanania T, Hopkins SC, Olivier B, Groenink L (2008) Translational aspects of pharmacological research into anxiety disorders: the stress-induced hyperthermia (SIH) paradigm. Eur J Pharmacol 585:407-425

Vinkers CH, Klanker M, Groenink L, Korte SM, Cook JM, Van Linn ML, Hopkins SC, Olivier B (2009) Dissociating anxiolytic and sedative effects of GABA(A)ergic drugs using temperature and locomotor responses to acute stress. Psychopharmacology (Berl) 204:299-311

West CH, Weiss JM (2005) A selective test for antidepressant treatments using rats bred for stress-induced reduction of motor activity in the swim test. Psychopharmacology (Berl) 182:9-23 